\title{
Verantwoordelijkheid, veiligheid en strafrecht
}

\author{
Over het bestraffen van feilbaarheid*
}

Willem-Jan Kortleven

\begin{abstract}
Deze bijdrage analyseert strafzaken tegen professionals na incidenten en ongelukken - een onderbelicht fenomeen - als pogingen om de maatschappelijke illusie van maakbaarheid te herstellen en morele sentimenten te bevredigen. Straf voor individuele professionals blijkt echter veel verzet onder collega-professionals te genereren en weinig maatschappelijk enthousiasme op te leveren. Bovendien wijzen veiligheidswetenschap en -praktijk erop dat het bestraffen van professionele fouten gemakkelijk leidt tot méér onveiligheid én de realiteit miskent dat systeemfactoren doorgaans in belangrijker mate bijdragen aan ongelukken dan individuele fouten. Dat roept de vraag op of strafrechtelijke verantwoordelijkheid voor ongelukken op systeemniveau gesitueerd moet worden, zoals in recente strafzaken tegen gemeentelijke overheden gebeurde. Een korte verkenning leidt tot de conclusie dat het bestraffen van 'systeembeheerders' ondanks positieve kanten ook negatieve consequenties kan hebben. Idealiter zouden bestuurders de behoefte aan strafrecht reduceren door pro-actiever en ruimhartiger verantwoordelijkheid te nemen voor het aandeel van hun organisatie in ongelukken.
\end{abstract}

\section{Inleiding}

Wie wil weten wat verantwoordelijkheid voor veiligheid concreet betekent, kan wijzer worden door de nasleep van incidenten, ongelukken en rampen te bestuderen. Juist bij een tekort aan veiligheid wordt zichtbaar aan wie dat wordt toegerekend en welke consequenties eraan worden verbonden. Niet dat dit een statisch beeld oplevert. Opvattingen over verantwoordelijkheidstoedeling voor veiligheid zijn divers en dynamisch. In dit verband verdient een ontwikkeling aandacht die vooral in de jaren 2000 zichtbaar is geworden: de opkomst van de neiging om professionals strafrechtelijk aan te spreken op onveiligheid. Zo werden in 2002 drie luchtverkeersleiders veroordeeld vanwege een bijna-botsing tussen twee verkeersvliegtuigen in 1998 (Kortleven, Putman, \& Waaijer, 2017, p. 304) en werd een paar jaar later de gezinsvoogd van het meisje Savanna, in 2004 overleden aan de gevolgen van mishandeling, vervolgd voor schuldige nalatigheid (Kuijvenhoven \& Kortleven, 2010, p. 1165). Hoewel de luchtvaart en de jeugdzorg nooit vrij van veiligheidsincidenten zijn geweest, waren professionele fouten in deze sectoren eerder zelden of nooit aanleiding voor strafrechtelijke vervolging.

* Dr. mr. W.J. Kortleven is universitair docent Bestuurskunde aan de Vrije Universiteit Amsterdam. Hij doet onderzoek naar vraagstukken van maakbaarheid en verantwoordelijkheid met betrekking tot fysieke en sociale veiligheid. 
Deze strafzaken symboliseren een kwalitatieve verandering in de omgang met het verantwoordelijkheidsvraagstuk. Waar professionals strafrechtelijk worden aangesproken op dingen die mis gaan, wordt hun verantwoordelijkheid voor veiligheid niet langer opgevat als inspanningsverplichting, maar als resultaatverplichting (Kortleven, 2013, pp. 351-355). Daarbij is het lastige dat het te behalen resultaat bestaat in de afwezigheid van iets, namelijk incidenten en erger. Ieder incident is dan een potentieel bewijs van tekortschieten.

De inzet van het strafrecht geeft de verantwoordelijkheidskwestie bovendien een extra morele lading, want het formuleert deze in termen van schuld en boete. Op zich is het geen nieuwe observatie dat de verantwoordelijkheid voor veiligheid een morele betekenis heeft. De antropoloog Mary Douglas heeft er meer dan eens op gewezen dat het oorspronkelijk neutrale begrip risico in de westerse wereld een vergelijkbare rol heeft gekregen als de begrippen zonde en taboe eerder hadden: het biedt 'a uniform vocabulary for moralizing and politicizing the dangers around' (Douglas, 1992, p. 26). Maar de strafrechtelijke aanpak van professionals betekent wel een ongekende explicitering van de vaak verstopte morele lading van veiligheidsvraagstukken. Een strafrechtelijke vervolging (zelfs als geen veroordeling of straf volgt) is één van de krachtigste en zichtbaarste vormen die een moreel verwijt in onze samenleving kan aannemen.

In deze bijdrage analyseer ik de betekenis en gevolgen van strafrechtelijke reacties op incidenten, ongelukken en rampen. Zo hoop ik bij te dragen aan een beter begrip van de huidige maatschappelijke omgang met verantwoordelijkheid voor veiligheid. De bijdrage is als volgt opgebouwd. Na een bespreking van relevante casuïstiek in Nederland duid ik strafrechtelijke reacties op onveiligheid primair als vorm van betekenisgeving en expressie van morele sentimenten. Vervolgens besteed ik aandacht aan de vraag of het strafrecht in dezen ook een preventieve functie toegedicht kan worden, mede in het licht van empirische inzichten over de averechtse effecten die het straffen van professionals in risicovolle sectoren kan hebben. Tot slot reflecteer ik op de vraag in hoeverre de voorgaande analyses opgaan als het strafrecht niet op individuele professionals wordt gericht, maar op de instanties die zij vertegenwoordigen.

\section{Strafzaken tegen professionals: casuïstiek in Nederland}

De strafzaak tegen drie luchtverkeersleiders die in de inleiding werd genoemd, was de eerste van twee zaken die de burgerluchtvaartsector in de jaren 2000 stevig opschudden. In wat deels bedoeld was als proefproces, oordeelde de rechter in eerste aanleg dat twee van de drie luchtverkeersleiders schuld droegen aan de bijna-botsing tussen twee vliegtuigen; zij werden veroordeeld tot boetes. In hoger beroep, eind 2002, werden zij alle drie schuldig verklaard zonder strafoplegging. Twee maanden na die uitspraak, begin 2003, vond een nieuw incident plaats dat voor het Openbaar Ministerie (OM) aanleiding was om een strafzaak te beginnen. Een passagiersvliegtuig raakte bij het maken van snelheid met de 'staartslof' de baan, waarna de start moest worden afgebroken. De gezagvoerder zou op de 
hoogte zijn geweest van het feit dat het grootste deel van de passagiers achter in het toestel zat, wat gezien werd als oorzaak van de tailstrike. De strafzaak tegen de gezagvoerder liep echter uit op vrijspraak omdat de rechter het geleverde bewijs voor een causaal verband tussen stoelverdeling en tailstrike onvoldoende hard achtte (Kortleven et al., 2017, p. 304).

Rond dezelfde tijd kwam de jeugdzorgsector onder een maatschappelijk vergrootglas te liggen. Verschillende geruchtmakende gevallen van kinderdoding door (stief)ouders vormden aanleiding voor media en toezichthouders om - voor het eerst - de rol te belichten van instanties en professionals die bij de betreffende gezinnen betrokken waren. Nadat de sector door de Bolderkar-affaire in 1988 de gevaren van overijverig ingrijpen had ingeprent gekregen, ging nu het beeld domineren van jeugdzorgwerkers die tekortschoten in hun beschermingstaak. In deze context viel het historische besluit om de gezinsvoogd van Savanna te vervolgen wegens nalatigheid; niet eerder werd een jeugdzorgprofessional op zo'n manier verantwoordelijk gehouden voor de dood van een kind. Eind 2007 werd de gezinsvoogd echter vrijgesproken, omdat de rechtbank een causaal verband tussen haar fouten en de fatale mishandeling van Savanna onbewezen achtte (Kortleven, 2013, pp. 202-203; Kuijvenhoven \& Kortleven, 2010, p. 1165).

Opmerkelijk is dat deze strafzaken in beide sectoren heftige reacties opriepen van professionals die zich identificeerden met hun aangeklaagde collega's. Vanuit de burgerluchtvaartsector werd een stevige lobby gevoerd voor een terughoudender opstelling van het OM. Deze had politiek succes: op instigatie van de minister van Justitie werd eind 2006 de 'Aanwijzing opsporing en vervolging bij melding van voorvallen in de burgerluchtvaart' van kracht. De kern daarvan is dat vervolging wordt gereserveerd voor ongevallen en ernstige incidenten veroorzaakt door opzet of grove nalatigheid. Fouten die een professional maakt terwijl hij zijn werk naar eer en geweten uitvoert, worden niet bestraft, ook niet als deze ernstige consequenties hebben. Het $\mathrm{OM}$ heeft sindsdien meer energie gestoken in het krijgen van een goede relatie met de sector dan in strafzaken. Inmiddels is er in de burgerluchtvaart al meer dan tien jaar niemand vervolgd (Kortleven et al., 2017, pp. 305-306).

De strafzaak tegen de gezinsvoogd van Savanna was aanleiding voor een demonstratie van jeugdzorgwerkers uit het hele land (Jungmann, 2006). Bovendien kregen criticasters van het proces veel ruimte in de media; onder hen jeugdzorgwerkers, de advocaten van de gezinsvoogd en zelfs de baas van de Inspectie jeugdzorg, wier rapport over de hulpverlening aan Savanna voor het OM de aanleiding vormde voor de strafzaak (Kuijvenhoven \& Kortleven, 2010, pp. 1165-1166). Jeugdzorgwerkers zaten ook massaal op de publieke tribune tijdens het proces, en applaudisseerden toen de gezinsvoogd van Savanna werd vrijgesproken (Salm, 2007). Het OM ging niet in beroep tegen de vrijspraak, en deze strafzaak is de enige in de sector is gebleven. Ook in de jeugdzorg is al meer dan tien jaar niemand vervolgd. 
De ontwikkelingen met betrekking tot de inzet van het strafrecht in de luchtvaart en de jeugdzorg vertonen dus veel gelijkenissen: ontluikende belangstelling van het OM voor professionele missers die eerder geen strafrechtelijke aandacht kregen, ongeveer in dezelfde periode, strafzaken die in de rechtszaal weinig opleveren (schuldig zonder strafoplegging of vrijspraak) en vanuit de 'getroffen' sectoren veel protest oproepen, waarna het OM terugvalt op een terughoudender opstelling. Daarmee kunnen deze strafzaken worden gezien als strafrechtelijke experimenten, 'proefprocessen', die kennelijk anders uitpakten dan het OM gehoopt of verwacht had.

De dynamiek van het OM-optreden en de parallelle patronen in twee heel verschillende contexten suggereren dat we voor het begrijpen van de achtergronden van deze strafzaken niet uitsluitend of zelfs niet in de eerste plaats moeten zoeken naar gelijkenissen tussen incidenten of professionals. De verschillen tussen professionals en incidenten in beide sectoren lijken te overheersen. Zo verhouden luchtverkeersleiders die de routes van komende en gaande vliegtuigen regisseren, of een piloot die actief bezig is met de voorbereiding en uitvoering van een start, zich op een andere, meer directe manier tot risico's dan een gezinsvoogd, die onvermijdelijk op afstand staat van de gezinnen in haar caseload en niet in staat is om deze continu te monitoren. Een ernstig geval van kindermishandeling lijkt in vrijwel niets op een bijna-botsing tussen twee vliegtuigen. De inzet van het strafrecht kan dan ook worden geduid als de manifestatie van dieperliggende maatschappelijke ontwikkelingen, waarvoor concrete incidenten een min of meer toevallig aangrijpingspunt vormden. Daarover gaan de volgende twee paragrafen, maar eerst loont het de moeite om nog naar een andere sector te kijken.

In de medische sector zijn strafzaken naar aanleiding van professionele fouten namelijk iets minder zeldzaam dan in de burgerluchtvaart en de jeugdzorg. In een interview van vijf jaar geleden stelde een officier van justitie verbonden aan het Expertisecentrum Medische Zaken van het Openbaar Ministerie dat er per jaar zo'n tien medische strafzaken per jaar voor de rechter komen, waarvan ongeveer de helft bestaat uit grote zaken (Waaijer, 2013, p. 39). In deze sector bestaan wel historische voorbeelden van strafzaken: honderd jaar geleden werd er al weleens een arts of verpleegkundige vervolgd. Maar ook hier geldt dat het OM zich recentelijk actiever is gaan opstellen. Er wordt vaker aangifte gedaan tegen medische professionals dan voorheen en het aantal strafrechtelijke onderzoeken is in reactie daarop toegenomen. Dat heeft volgens een aantal door Waaijer geïnterviewde officieren van justitie echter niet geleid tot meer vervolgingen: veel onderzoeken worden voor alle zekerheid uitgevoerd, om een beslissing tot niet-vervolging beter te kunnen onderbouwen en zo steviger te staan bij een eventuele artikel 12 Sv-procedure (Waaijer, 2013, pp. 47-49; Kortleven et al., 2017, p. 312). Tegelijkertijd zijn er geen aanwijzingen dat het optreden van het $\mathrm{OM}$ in de medische sector een zelfde actie-reactie-patroon heeft gevolgd als in de andere besproken sectoren. Hier ontbreken heftige reacties op strafzaken die het OM naar een terughoudender opstelling konden laten terugkeren. 


\section{Incidenten en ongelukken als bewijs van menselijk falen}

We kunnen de opkomst van strafrechtelijke reacties op incidenten en ongelukken deels begrijpen als de vrucht van processen zoals democratisering, informatisering en juridisering. Het opleidingspeil is gestegen, mensen hebben meer kennis, betere toegang tot relevante informatie en zijn mondiger geworden (Dekker, 2009 , p. 70). Het vanzelfsprekende gezag dat professionals en instanties ooit hadden, is mede daardoor voor een belangrijk deel verdwenen, en daarmee ook een belangrijke drempel om hen onder kritiek te stellen voor fouten waarmee zij voorheen 'weg konden komen'. De juridisering van de samenleving, mede verklaarbaar door het vermogen van het recht om toenemende maatschappelijke diversiteit te overbruggen (Chevalier, 2016, p. 117), maakt vervolgens het aanspannen van een strafrechtelijke procedure vanzelfsprekender, of het initiatief daarvoor nu van de burger komt of van het Openbaar Ministerie.

Voor een goed begrip van dit fenomeen moeten we echter nog dieper graven, om uit te komen bij de toegenomen maakbaarheidspretenties in onze samenleving en de algemeen-menselijke neiging om onheil van een betekenis te voorzien. In de loop van de tijd heeft de menselijke invloed zich zodanig uitgebreid over allerlei terreinen, dat er bijna geen gebeurtenissen of situaties meer denkbaar lijken waarop geen menselijke grip mogelijk is.

Deze ontwikkeling heeft grofweg twee reacties opgeroepen. De eerste reactie, waarvan Charles Perrow (1984) en Ulrich Beck (1986; 1992) prominente vertolkers zijn, wijst op de negatieve of zelfs catastrofale kanten van de toegenomen menselijke invloed. Technologische ontwikkelingen hebben nieuwe gevaren in het leven geroepen, die reeds talloze levens hebben geëist (industrialisering, wegverkeer) dan wel de toekomst van hele volksstammen of zelfs de aardbol bedreigen (nucleaire technologie, klimaatverandering). In deze visie is zowel menselijke terughoudendheid als menselijke actie geboden. De maakbaarheidspretenties moeten worden teruggeschroefd, de menselijke neiging om de werkelijkheid te 'instrumentaliseren' moet worden bedwongen, de donkere keerzijde van menselijke activiteit moet onder ogen worden gezien. Tegelijkertijd dient verantwoordelijkheid te worden genomen voor de schade die al is aangericht of dreigt te worden aangericht en moeten maatregelen worden genomen om te redden wat er te redden valt. Dat is de paradox: nu de mens de boel al een heel eind heeft verknoeid, kan hij het zich niet meer permitteren om zich terug te trekken. De maakbaarheidspretenties kunnen toch niet helemaal in de ijskast, maar moeten nu voor de goede zaak worden aangewend: het beschermen van mensenlevens en het redden van de planeet (Kortleven, 2013, pp. 62-63).

De tweede reactie, indirecter en implicieter van aard, is juist ingegeven door de positieve kanten van de toegenomen menselijke invloed. Door menselijke innovatie is de bescherming tegen natuurlijke gevaren en ziekten enorm verbeterd, de verzorgingsstaat heeft zijn deel bijgedragen aan de toename van welvaart en gezonde levensjaren, en het is ook een heel eind gelukt om risicovolle technologie veiliger te maken. Dat heeft geleid tot stijgende verwachtingen van wat mensen 
vermogen en tot een dalende tolerantie ten aanzien van de resterende onveiligheid (Dekker, 2009, p. 70; Pieterman, 2008, pp. 76, 82).

In de praktijk lopen beide soorten reacties vaak door elkaar en zijn zij nauwelijks te ontwarren. Dat is ook niet zo verwonderlijk: ondanks de verschillen in uitgangspunt komen zij uit op ongeveer dezelfde moraal. In de woorden van François Ewald (2002, p. 292): 'Morality becomes a sort of negative morality: it is not so much turned toward the positive quest for the best as toward the avoidance of the worst.' Het vermijden van onveiligheid wordt een dure plicht, die in belangrijke mate wordt gedragen door professionals, als vertegenwoordigers van de expertise en systemen waarop onze maakbaarheidspretenties steunen (vgl. Giddens, 1990, pp. 27-29).

Deze ontwikkeling lijkt de menselijke behoefte om betekenis te geven aan onheil een nieuwe impuls en specifieke wending te hebben gegeven. Het is voor mensen moeilijk te accepteren dat een gebeurtenis die hun wereld op zijn grondvesten doet schudden, stom toeval is. In vroeger tijden nam men daarom vrij algemeen de toevlucht tot verklaringen als magie, een gebroken taboe, zonde of een goddelijke bedoeling. De moderniteit bracht een rationeler wereldbeeld, waarin ongevallen een statistisch gegeven zijn zonder dieperliggende betekenis (Dekker, 2009, p. 69-70; Douglas \& Wildavsky, 1982, p. 31). Maar volgens Mary Douglas (1992, p. 16) blijkt dat nu een intermezzo te zijn, een tijdelijke (en plaatselijke?) afwijking van de neiging achter ieder onheil een verklaring te zoeken. We zijn weer teruggevallen op die 'primitieve mentaliteit' (Douglas \& Wildavsky, 1982, p. 31), zij het met handhaving van de wetenschappelijke jas (Dekker \& Nyce, 2012, p. 211). De bovennatuurlijke verklaringen zijn vervangen door verklaringen die de alomtegenwoordige invloed (en dus verantwoordelijkheid) van mensen veronderstellen. Zoals Sidney Dekker stelt: 'Accidents today are seen as evidence that a particular risk was not managed well enough. And behind such mismanagement there are people, single persons, or single acts of omission or commission by those persons' (Dekker, 2009, p. 70).

Een frappante casus in dit verband is die van de Italiaanse seismologen die in 2012 werden veroordeeld tot zes jaar cel omdat zij een inadequate risicoanalyse zouden hebben gemaakt van de trillingen die voorafgingen aan een zware aardbeving. Het adjunct-hoofd van de civiele beschermingsdienst kreeg dezelfde straf, omdat hij de bevolking ten onrechte had gerustgesteld. Zelfs aardbevingen, die bij uitstek kunnen worden aangeduid met de traditionele maar nog steeds gangbare term acts of God, blijken dus binnen het bereik van de menselijke verantwoordelijkheid te zijn gebracht. In hoger beroep en in cassatie werden de seismologen overigens vrijgesproken, tot woede van nabestaanden. De veroordeling van de ambtenaar bleef wel in stand, maar zijn straf werd teruggebracht tot twee jaar (Cartlidge, 2015). 


\section{Herstel van illusies en expressie van emoties?}

Tegen de geschetste achtergrond kan de inzet van het strafrecht na incidenten, ongelukken of rampen het best worden begrepen als een van de krachtigste manieren die voorhanden zijn om de geschonden norm en de illusie van maakbaarheid te herbevestigen en de emoties die daarmee gepaard gaan van een uitlaatklep te voorzien. Een ongeluk kan worden opgevat als bewijs van het tekortschieten van de menselijke controle over de loop der dingen, maar als het ongeluk voortkomt uit een normoverschrijding, kan het idee van maakbaarheid toch staande worden gehouden. Immers, als iedereen normaal gehandeld zou hebben, zou het ongeluk niet gebeurd zijn.

Volgens Dekker en Nyce (2012, pp. 210-211) is het idee dat een ongeluk gebeurd kan zijn ondanks het feit dat niemand een duidelijk aanwijsbare fout heeft gemaakt heel bedreigend, omdat het onzekerheid en een gebrek aan controle impliceert. Het tast onze overtuiging aan dat we weten hoe de wereld werkt (vgl. Turner, 1978). Daarom is het zo belangrijk om iemand te vinden die iets fout heeft gedaan, waarbij geldt: 'accuracy or fairness matters less than closing or reducing the anxiety associated with having no cause at all' (Dekker \& Nyce, 2012, p. 211). Angst voor verlies van controle en boosheid over de normoverschrijding die het ongeluk zou hebben veroorzaakt, vormen de drijvende kracht achter het bestraffen van degenen die we verantwoordelijk houden.

Dit kan worden gezien als een Durkheimiaanse interpretatie. Volgens Durkheim wordt straf niet adequaat begrepen wanneer we focussen op manifeste strafdoelen als preventie en gedragsbeïnvloeding. Inzet van het strafrecht wordt in de kern gedreven door een emotionele reactie op de schending van collectieve waarden (Garland, 1990, pp. 32-33; Garland, 2013, pp. 23-26). Door te fungeren als collectieve uitdrukking én bevrediging van morele sentimenten, opgeroepen door een misdaad, zou straf vervolgens degenen bij elkaar brengen bij wie deze sentimenten leven (Durkheim, 1984/1893, pp. 57-60, 62-63). Een vergelijkbare dynamiek signaleert Boutellier (1993) in deze tijd rondom de notie van 'slachtofferschap': in onze afwijzing van wat slachtoffers is aangedaan, vinden we elkaar.

Een belangrijke vraag is echter of gevaarlijke en fatale fouten van professionals een geschikt richtpunt vormen voor de expressie van de morele sentimenten die worden opgeroepen door incidenten, ongelukken en rampen. Het is de gang van zaken in de besproken casuïstiek die de voedingsbodem vormt voor deze vraag: de maatschappelijke solidariteit die volgens Durkheim gediend wordt door de schender van collectieve normen te straffen, wordt daar niet echt zichtbaar. Wat opvalt, is juist dat strafzaken tegen professionals stevig protest van collega-professionals hebben opgeroepen, en vanuit de samenleving op weinig steun konden rekenen.

Illustratief is dat tijdens de strafzaak tegen de gezinsvoogd van Savanna vaak te horen was dat niet zij, maar de moeder en stiefvader van Savanna verantwoordelijk waren voor de dood van het meisje. Vanuit Durkheimiaans perspectief 
vormde de strafzaak tegen deze direct verantwoordelijken dan ook een meer voor de hand liggende gelegenheid voor de uitdrukking van morele emoties. Relevant is ook dat de meeste dagbladen veel ruimte gaven aan criticasters van het proces tegen de gezinsvoogd. Slechts enkele dagbladen brachten in hun redactionele commentaren expliciet begrip op voor de beslissing om de gezinsvoogd te vervolgen. De meeste redactionele commentaren plaatsten naar aanleiding van de strafzaak niet zozeer kritische noten bij het handelen van de individuele gezinsvoogd, maar bij het functioneren van jeugdzorgorganisaties en het jeugdzorgsysteem in het algemeen. Dat lijkt te duiden op publieke steun voor de gedachte dat hier de enkeling tot zondebok gemaakt werd voor het falen van het systeem (Kuijvenhoven \& Kortleven, 2010, pp. 1165-1166).

Hoewel het aannemelijk is dat de emoties van directe (nabestaanden van) slachtoffers van een ongeluk of ramp zo sterk zijn dat zij gemakkelijk kunnen leiden tot de wens om individuen te straffen die verantwoordelijk kunnen worden gehouden, lijkt het dus niet vanzelfsprekend dat die neiging om individuen te straffen buiten de kring van direct betrokkenen breed gedeeld wordt. Dat kan worden verklaard doordat missers van mensen die naar eer en geweten hun werk doen, zich bevinden op de buitengrens van wat algemeen als strafwaardig wordt gezien. Het gaat niet om criminaliteit in de gebruikelijke zin van het woord. Het is daarbij aannemelijk dat veel mensen zich kunnen inleven in een professional die tegen wil en dank zo'n misser begaat: iedereen maakt weleens een fout in het werk, hoewel niet iedereen werk heeft waarin fouten ernstige consequenties kunnen hebben. Het bestraffen van een falende professional kan daarom maar moeilijk maatschappelijke solidariteit genereren, voor zover het althans gaat om solidariteit die zich afzet tégen de bestrafte. De protesten in luchtvaart en jeugdzorg laten zien dat het bestraffen van een professional wel solidariteit mét de bestrafte kan oproepen, in ieder geval onder collega-professionals. Laten we dat - met een knipoog naar Durkheim - omgekeerde solidariteit noemen.

Dit helpt verklaren waarom de strafzaken in de burgerluchtvaart en jeugdzorg in de jaren 2000 de indruk wekken van mislukte experimenten. Ze kunnen worden gezien als proefprocessen, niet zozeer in de gebruikelijke juridische betekenis, maar in sociologische zin: door een vervolging te starten kom je erachter in hoeverre de samenleving dit soort zaken, als uiterste consequentie van haar eigen risico-aversie, steunt. Dat het in de genoemde sectoren tot nu toe is gebleven bij enkele strafzaken, alweer meer dan tien jaar geleden, duidt erop dat het Openbaar Ministerie uit de reacties op deze sociologische proefprocessen heeft geconcludeerd dat de maatschappelijke steun tekortschiet.

\section{Veiligheidsinstrument of veiligheidsrisico?}

De Durkheimiaanse nadruk op straf als expressie en bevrediging van morele emoties - en de daarmee gepaard gaande relativering van een strafdoel als preventie neemt niet weg dat preventie voor het strafrechtsapparaat wel degelijk een belangrijke drijfveer kan zijn. Dat blijkt bijvoorbeeld uit de interviews die Waaijer 
hield met medische officieren van justitie. Zij zien voor zichzelf een cruciale rol weggelegd in het vergroten van het lerend vermogen en daarmee de veiligheid in de medische sector. Vanwege hun buitenstaanderschap en strafrechtelijke repertoire zouden zij soms beter dan de tuchtrechter en de Inspectie voor de Gezondheidszorg in staat zijn om meer openheid over medische missers te bereiken, artsen in voorkomende gevallen tot inzicht te dwingen, verantwoordelijkheidsbesef en alertheid te bevorderen, en normen te verhelderen en te bevestigen (Kortleven et al., 2017, pp. 312-313).

Het probleem is dat er weinig empirische basis is om erop te vertrouwen dat de strafrechtelijke aanpak van falende professionals daadwerkelijk bijdraagt aan de reductie van onveiligheid. Tegelijkertijd is er wel empirische kennis die uitwijst dat straf onveiligheid kan bevorderen. Het is belangrijk hier onderscheid te maken tussen honest mistakes van professionals die naar eer en geweten hun werk doen, en gevaarlijk handelen dat voortkomt uit grove nalatigheid, roekeloosheid of zelfs opzet. Een strafrechtelijke aanpak van gevaarlijk handelen dat voortkomt uit een verkeerde werkhouding kan nuttig zijn, omdat het bijdraagt aan helderheid over de geldende normen en omdat afzien van bestraffing demotiverend zou werken voor collega-professionals die hun werk wel vanuit de juiste motivatie doen. Een strafrechtelijke aanpak van 'eerlijke fouten', of ze nu voortkomen uit een moment van onbedachtzaamheid, vermoeidheid of iets anders, brengt een levensgroot risico op averechtse effecten met zich mee (Reason, 1998, pp. 302-305).

Zo kan straf goedwillende professionals psychologisch belasten, zeker omdat betrokkenheid bij een incident of ongeluk op zichzelf al belastend kan zijn. Zulke secondary victimization heeft uiteraard invloed op het functioneren van deze professionals en daarmee op het functioneren van het systeem waarin zij opereren (Dekker, 2011, pp. 123-125). Bestraffing van fouten leidt bovendien gemakkelijk tot een verkeerd soort afschrikking: professionals kunnen uit vrees voor straf defensief gaan handelen. Gerichtheid op het vermijden van straf staat echter niet gelijk aan op veiligheid gericht handelen.

Dat risico wordt vooral zichtbaar in het negatieve effect dat straf kan hebben op de bereidheid om fouten en incidenten te melden. Anders dan de medische officieren van justitie veronderstellen, leidt straf eerder tot minder dan tot meer openheid. Dat bleek bijvoorbeeld in de luchtvaartsector, waar in de nasleep van de besproken strafzaken het aantal incidentmeldingen door luchtverkeersleiders daalde met meer dan 50 procent (Kortleven et al., 2017, pp. 305-306). In de veiligheidspraktijk en veiligheidswetenschap worden dergelijke meldingen echter juist cruciaal geacht voor het bevorderen van veiligheid. Voor Reason (1998) staat een safe culture gelijk aan een informed culture, waarin zoveel mogelijk relevante informatie over potentiële veiligheidsrisico's de managers van het systeem bereikt. Voor een informed culture is een reporting culture essentieel: iedereen moet zich vrij en aangemoedigd voelen om relevante informatie te melden, juist ook over eigen missers. Aan de basis daarvan ligt een just culture, waarin honest mistakes geen straf opleveren, maar het rapporteren ervan veeleer beloond wordt (zie 
ook Dekker, 2011; 2012). Dit idee van een just culture is diep verankerd in de Nederlandse burgerluchtvaart, en de koerswijziging die het OM vanaf 2006 in deze sector heeft ingezet, sluit daarbij aan.

Bestraffing van individuele professionals doet bovendien geen recht aan de werkelijkheid, waarin een ongeluk ontstaat uit een combinatie van allerlei factoren, waarvan de individuele fout aan de frontlijn niet per se de belangrijkste factor is. Voor complexe organisaties met veel veiligheidswaarborgen geldt volgens Reason zelfs dat fouten van individuen op zichzelf geen groot veiligheidsrisico vormen. Tegen individuele fouten is het systeem grotendeels bestand, tenzij er sprake is van latente ontwerpfouten of van een disfunctionele cultuur. Pas als individuele fouten aan de frontlijn interacteren met ontwerpfouten, of als op individuele fouten verkeerd gereageerd wordt (bijvoorbeeld door het melden van fouten af te straffen, waardoor essentiële veiligheidsinformatie onder de pet blijft), kunnen zij uitgroeien tot ongelukken met een grotere reikwijdte. Dit perspectief maakt duidelijk dat niet individuele professionals de zwaarste verantwoordelijkheid dragen voor onveiligheid, maar de beheerders van de complexe systemen waarin professionals acteren (Reason, 1990; 1998; Hudson, 2001).

Een gerichtheid op individuele fouten en het bestraffen van schuldigen betekent veelal dat men verzuimt dieperliggende oorzaken en contextuele factoren bloot te leggen en verhindert daardoor een adequaat begrip van de gebeurtenis in kwestie en verbetering in de toekomst. Het leidt bovendien af van de verantwoordelijkheid van systeembeheerders. De realiteit is dan ook vaak dat straf in de plaats komt van daadwerkelijke verbetering van de context waarin een ongeluk kon ontstaan (Dekker, 2011, p. 124).

\section{Slot: liever instanties bestraffen?}

Gezien de bezwaren tegen het bestraffen van individuele fouten en gezien de waarschijnlijk niet uitroeibare behoefte aan straf als uitlaatklep voor de emoties opgewekt door een ongeluk of ramp, is het de vraag of deze spanning oplosbaar is in een gulden middenweg of een acceptabel compromis. Heel interessant zijn in dit verband twee relatief recente strafzaken naar aanleiding van dodelijke verkeersongevallen, waarin niet professionals maar gemeentelijke overheden vervolgd werden.

Naar aanleiding van een dodelijk ongeval met een motor in 2009 vervolgde het OM de gemeente Stichtse Vecht in haar hoedanigheid als wegbeheerder voor dood door schuld. Het ongeval was veroorzaakt door hobbels in het wegdek: de gemeente werd verweten dat zij verzuimde het wegdek te egaliseren of waarschuwingstekens aan te brengen. De gemeente werd eind 2012 veroordeeld tot het betalen van een (deels voorwaardelijke) geldboete en ging niet in beroep (Kortleven, 2013, pp. 155-156). Een half jaar later gebeurde er in Amsterdam een dodelijk ongeval op de Veemkade dat voor het OM aanleiding was de gemeente een strafbeschikking op te leggen. Ook hier ging het om een gevaarlijke verkeerssitua- 
tie (Swanenberg, 2015, p. 6; Het Parool, 2015). In deze twee zaken werden voor het eerst strafrechtelijke consequenties verbonden aan de verantwoordelijkheid van wegbeheerders voor een veilige weginrichting. Onlangs bepaalde de Hoge Raad naar aanleiding van de zaak in Stichtse Vecht dat een gemeente inderdaad kan worden vervolgd voor een ongeval als gevolg van slecht wegonderhoud.

Zijn dit voorbeelden ter navolging? Wat positief te waarderen valt aan het straffen van instanties is dat de functie van uitlaatklep beschikbaar is, zonder de nadelen die gepaard gaan met het straffen van individuen, zoals de psychologische effecten. Bovendien doet het strafrechtelijk aanspreken van een instantie meer recht aan het inzicht dat een ongeluk vrijwel nooit alleen aan individuen te wijten is, maar samenhangt met het systeem en de cultuur waarbinnen deze individuen opereren. Het heeft een zekere logica om dan ook de verantwoordelijkheid op het systeemniveau te lokaliseren.

Tegelijkertijd zijn twijfels gerechtvaardigd. Zo is goed denkbaar dat het strafrechtelijk aanspreken van instanties een minder bevredigend effect heeft dan de bestraffing van individuen verondersteld wordt te hebben (maar zie de nuances die eerder in dit artikel zijn aangebracht), mede gezien het gegeven dat een instantie geen gezicht heeft, niet de gevangenis in kan, en een eventuele boete met gemeenschapsgeld zal betalen. Tenslotte is het strafrecht niet echt toegesneden op (publiekrechtelijke) rechtspersonen (Swanenberg, 2015, p. 46).

Het lijkt daarbij realistisch om rekening te houden met het scenario dat de focus op instanties en het systeemniveau uiteindelijk weer zou kunnen leiden tot het strafrechtelijk aanspreken van vertegenwoordigers van die instanties en systemen, is het niet een frontlijnwerker dan wel een eindverantwoordelijke, die anders dan de instantie wel een gezicht heeft. Het strafrechtelijke bloed kruipt wellicht waar het niet gaan kan ...

Daarnaast is de vraag relevant welke invloed de strafrechtelijke vervolging van instanties heeft op het functioneren ervan. In het ideale geval functioneren vervolging en eventuele veroordeling als een wake-up call, waardoor blinde vlekken alsnog onder ogen worden gezien en verantwoordelijkheden serieus worden genomen. In dat geval zou straf kunnen bijdragen aan het bevorderen van veiligheid. Maar is het gevaar niet groot dat het in de praktijk (ook) leidt tot risicomijdend gedrag en protocollendrift? Dat zou de algehele kwaliteit van het functioneren van die instanties waarschijnlijk niet ten goede komen (Swanenberg, 2015), en evenmin leiden tot meer veiligheid. Meer onderzoek is nodig om deze vragen te beantwoorden, want empirische gegevens over de invloed van het strafrecht op het functioneren van instanties zijn nog nauwelijks voorhanden. Het masterthesisonderzoek van Swanenberg (2015) vormt een bescheiden begin.

Gezien de twijfels over de strafrechtelijke aanpak van instanties zou het waarschijnlijk het meest verkieslijk zijn als een strafrechtelijke nasleep van (bijna-)ongelukken en rampen voorkomen kon worden. Wat daarbij mogelijk zou helpen, is als bestuurders na ongelukken en rampen pro-actiever en ruimhartiger 
verantwoordelijkheid nemen voor het aandeel van hun organisatie in de gebeurtenis. Wat de meeste burgers het belangrijkst vinden - dat maakt een tijdje snuffelen in rapporten van de Nationale Ombudsman wel duidelijk - is dat zij gehoord worden en dat hun leed erkend wordt. Wanneer in die behoeften wordt voorzien, lijkt de kans groter dat de morele verontwaardiging over dat wat niet had mogen gebeuren zich geen uitweg hoeft te zoeken via het strafrecht. Wellicht is zo'n opstelling voor de meeste bestuurders onhaalbaar, omdat het niet altijd gemakkelijk zal zijn om vroegtijdig te bepalen wanneer aanvaarding van verantwoordelijkheid gerechtvaardigd is, en omdat de (financiële) risico's waarschijnlijk niet gering zijn. Maar het lijkt me de moeite van een nadere overdenking waard.

\section{Literatuur}

Beck, U. (1986). Risikogesellschaft: Auf dem Weg in eine andere Moderne. Frankfurt am Main: Suhrkamp.

Beck, U. (1992). From industrial society to the risk society: Questions of survival, social structure and ecological enlightenment. Theory, Culture, and Society, 9, 97-123.

Boutellier, J.C.J. (1993). Solidariteit en slachtofferschap: De morele betekenis van criminaliteit in een postmoderne cultuur (proefschrift Amsterdam UvA). Nijmegen: SUN.

Cartlidge, E. (2015, 20 november). Italy's supreme court clears L'Aquila earthquake scientists for good. Science News. Verkregen op 4 februari 2018 via http://sciencemag.org/ news/2015/11/italy-s-supreme-court-clears-l-aquila-earthquake-scientists-good.

Chevalier, D. (2016). 'The production of law': Law in action in the everyday and the juridical consequences of juridification. Recht der Werkelijkheid, 37(3), 116-133.

Dekker, S.W.A. (2009). Prosecuting professional mistake: Secondary victimization and a research agenda for criminology. International Journal of Criminal Justice Sciences, 4(1), 60-78.

Dekker, S. (2011). The criminalization of human error in aviation and healthcare: A review. Safety Science, 49(2), 121-127.

Dekker, S. (2012). Just culture: Balancing safety and accountability. Farnham: Ashgate.

Dekker, S.W.A., \& Nyce, J.M. (2012). Cognitive engineering and the moral theology and witchcraft of cause. Cognitive, Technology \& Work, 14, 207-212.

Douglas, M. (1992). Risk and blame: Essays in cultural theory. London/New York: Routledge.

Douglas, M., \& Wildavsky, A. (1982). Risk and culture: An essay on the selection of technological and environmental dangers. Berkeley etc.: University of California Press.

Durkheim, E. (1984/1893). The division of labor in society. New York: Free Press (oorspr. De la division du travail social).

Ewald, F. (2002). The return of Descartes' malicious demon: An outline of a philosophy of precaution. In T. Baker \& J. Simon (Eds.), Embracing risk: The changing culture of insurance and responsibility (pp. 273-301). Chicago/London: University of Chicago Press.

Garland, D. (1990). Punishment and modern society: A study in social theory. Oxford: Clarendon Press.

Garland, D. (2013). Punishment and social solidarity. In J. Simon \& R. Sparks (Eds.), The SAGE handbook of punishment and society (pp. 23-39). London: SAGE.

Giddens, A. (1990). The consequences of modernity. Cambridge: Polity Press.

Het Parool. (2015, 17 april). OM geeft gemeente boete van 15.000 euro voor dodelijk ongeluk Veemkade. Verkregen op 5 februari 2018 via www.parool.nl/amsterdam/om-geeftgemeente-boete-van-15-000-euro-voor-dodelijk-ongeluk-veemkade a3961948/. 
Hudson, P.T.W. (2001). Safety management and safety culture: The long, hard and winding road. In W. Pearse, C. Gallagher, \& L. Bluff (Eds.), Occupational health \& safety management systems: Proceedings of the First National Conference (pp. 3-31). Melbourne: Crown Content.

Jungmann, B. (2006, 22 december). Gezinsvoogden voelen zich 'vogelvrij'. De Volkskrant. Verkregen op 5 februari 2018 via www.volkskrant.nl/binnenland/gezinsvoogdenvoelen-zich-vogelvrij a805237/.

Kortleven, W.J. (2013). Voorzorg in Nederland: Ontwikkelingen in de maatschappelijke omgang met kindermishandeling, verkeersonveiligheid en genetische modificatie (proefschrift Erasmus Universiteit Rotterdam). Oisterwijk: Wolf Legal Publishers.

Kortleven, W.J., Putman, K., \& Waaijer, I. (2017). De officier van justitie als toezichthouder bij professionele fouten: Casestudy in de luchtvaartsector en de medische sector. In R. Staring, R. van Swaaningen, \& K. van Wingerde (red.), Over de muren van stilzwijgen: Liber amicorum Henk van de Bunt (pp. 301-314). Den Haag: Boom Criminologie.

Kuijvenhoven, T., \& Kortleven, W.J. (2010). Inquiries into fatal child abuse in the Netherlands: A source of improvement? British Journal of Social Work, 40(4), 1152-1173.

Perrow, C. (1984). Normal accidents: Living with high-risk technologies. New York: Basic Books.

Pieterman, R. (2008). De voorzorgcultuur: Streven naar veiligheid in een wereld vol risico en onzekerheid. Den Haag: Boom Juridische uitgevers.

Reason, J. (1990). The contribution of latent human failures to the breakdown of complex systems. Philosophical Transactions of the Royal Society of London. Series B, Biological Sciences, 327(1241), 475-484.

Reason, J. (1998). Achieving a safe culture: Theory and practice. Work \& Stress, 12(3), 293-306.

Salm, H. (2007, 17 november). Applaus na vrijspraak van gezinsvoogd Savanna. Trouw. Verkregen op 5 februari 2018 via www.trouw.nl/home/applaus-na-vrijspraak-vangezinsvoogd-savanna adf44f79/.

Swanenberg, J.M. (2015). Criminaliseren van overheidsfalen: Een kwalitatief onderzoek naar de invloed van het strafrecht op het handelen van gemeenten in de hoedanigheid van wegbeheerder (masterthesis Vrije Universiteit Amsterdam).

Turner, B.A. (1978). Man-made disasters. London: Wykeham.

Waaijer, I.K. (2013). Medische fouten: een strafbaar feit? Een onderzoek naar de perspectieven van het Openbaar Ministerie en medische professionals op het strafrechtelijk vervolgen van professionele fouten in de medische sector (masterthesis Vrije Universiteit Amsterdam). 